\title{
Endovascular Treatment of Very Small Intracranial Aneurysms: Meta-Analysis
}

\author{
(D).N. Yamaki, DW. Brinjikji, (D) M.H. Murad, and (D) Lanzino
}

\begin{abstract}
BACKGROUND AND PURPOSE: Outcomes of endovascular treatment of very small intracranial aneurysms are still not well-characterized. Recently, several series assessing coil embolization of tiny aneurysms have presented new promising results. Thus, we performed a systematic review and meta-analysis of studies evaluating endovascular treatment of very small intracranial aneurysms.
\end{abstract}

MATERIALS AND METHODS: We conducted a computerized search of Scopus, Medline, and the Web of Science for studies on endovascular treatment of very small ( $\leq 3 \mathrm{~mm}$ in diameter) intracranial aneurysms published between January 1996 and May 2015 . Using a random-effects model, we evaluated clinical and angiographic outcomes.

RESULTS: Twenty-two studies with 1105 tiny aneurysms (844 ruptured and 261 unruptured) endovascularly treated were included. Postoperative and long-term complete occlusion was achieved in $85 \%(95 \% \mathrm{Cl}, 78 \%-90 \%)$ and $91 \%(95 \% \mathrm{Cl}, 87 \%-94 \%)$ of aneurysms, respectively. The recanalization rate was $6 \%(95 \% \mathrm{Cl}, 4 \%-11 \%)$ and retreatment occurred in $7 \%(95 \% \mathrm{Cl}, 5 \%-9 \%)$ of cases. Seventy-nine percent (95\% Cl, 64\%-89\%) of patients had good neurologic outcome at long-term follow-up. Intraprocedural rupture occurred in $7 \%$ (95\% Cl, $5 \%-9 \%)$ of the coiling procedures, while thromboembolic complications occurred in $4 \%(95 \% \mathrm{Cl}, 3 \%-6 \%)$.

CONCLUSIONS: Coil embolization of very small intracranial aneurysms can be performed safely and effectively. In the case of unruptured aneurysms, procedure-related complications are not negligible. Patients and providers should consider such risks when engaged in a shared decision-making process.

ABBREVIATION: IA = intracranial aneurysm

$\mathbf{E}^{\mathrm{n}}$ ndovascular treatment is now the standard of care for most intracranial aneurysms (IAs). ${ }^{1,2}$ Despite endovascular treatment being safe with low morbidity and mortality rates, in certain groups of aneurysms, a detailed risk-benefit assessment of this treatment must be considered. ${ }^{3}$ Coil embolization of very small IAs ( $\leq 3 \mathrm{~mm}$ ) is particularly challenging due to the thin fragile wall of small IAs, with limited space to obtain a stable microcatheter position for coil deployment. ${ }^{4-6}$ In the Barrow Ruptured Aneurysm Trial, very small aneurysm size was one of the main rea-

Received August 18, 2015; accepted after revision November 10.

From the Coordenação de Aperfeiçoamento de Pessoal de Nível Superior Foundation (V.N.Y.), Ministry of Education of Brazil, Brasilia, Brazil; and Department of Radiology (W.B.), Center for Science of Healthcare Delivery (M.H.M.), and Department of Neurosurgery (G.L.), Mayo Clinic, Rochester, Minnesota.

Contributorship statement: Vitor N. Yamaki, Waleed Brinjikji, Mohammad H. Murad, and Giuseppe Lanzino participated in drafting the article and revising it critically for important intellectual content. These authors made substantial contributions to conception and design, acquisition of data, and analysis and interpretation of data. All authors provided final approval of the version to be published.

Please address correspondence to Waleed Brinjikji, MD, Mayo Clinic, OL 1-115, 200 SW First St, Rochester, MN 55905; e-mail brinjikji.waleed@mayo.edu; @wbrinjikji

http://dx.doi.org/10.3174/ajnr.A4651 sons for the high crossover rate from the coiling to the clipping group. $^{2}$ A previous meta-analysis that included only 7 studies observed a relatively high complication rate, especially in terms of periprocedural rupture risk. ${ }^{7}$ Since then, several technologic improvements, including better microcatheters and steerable soft microguidewires, compliant and easier-to-navigate balloons, and the availability of newer distal access catheters and very small endovascular coils have been developed, which may have enhanced our ability in coiling very small aneurysms. Since publication of the previous meta-analysis, many recent series have outlined results and complications in this specific subset of aneurysms.

In an attempt to examine the current safety and efficacy of endovascular treatment of tiny intracranial aneurysms, we performed an updated systematic review and meta-analysis of the literature addressing the endovascular treatment of very small intracranial aneurysms. We also compared results from studies included in a previously published meta-analysis from $2010^{7}$ with more recently published studies to determine whether there have been improvements in outcomes with time. We hypothesized that 
recently published studies would demonstrate lower intraoperative rupture rates and higher rates of aneurysm occlusion.

\section{MATERIALS AND METHODS}

\section{Literature Search}

Studies were identified by a search of Scopus, Medline, and the Web of Science for studies on the endovascular treatment of very small ( $\leq 3 \mathrm{~mm}$ in diameter) intracranial aneurysms published between January 1996 and May 2015. The search was performed by using the following keywords: "cerebral aneurysm," "intracranial aneurysm," "coil," "small," "tiny," and "endovascular" in both AND and OR combinations. The eligibility assessment of the articles was initially performed independently by 2 authors (W.B. and V.N.Y.). In case of disagreement, a third author (G.L.) was consulted for a final decision. Reference lists of included articles were scanned as an additional means of identifying articles.

\section{Study Selection}

Consecutive case series studying the endovascular treatment of very small intracranial aneurysms ( $\leq 3 \mathrm{~mm}$ in diameter) with $\geq 10$ patients were included in this meta-analysis. Participants of any age with very small saccular IAs were considered. Studies addressing dissecting or "blister" IAs were excluded because these lesions have unique natural histories and pathologic characteristics. Series studying IAs in a specific location were also excluded to avoid selection bias.

Patients were divided into 3 groups: 1) unruptured coiled aneurysms, 2) ruptured coiled aneurysms, and 3) stent-assisted coiled aneurysms, ruptured and unruptured. Patients who received a stent without coiling were added to the stent-assisted group. In 1 article, 1 patient was treated with Onyx (Covidien, Irvine, California), thus excluding the article from our analysis. No patients were treated with flow-diverting stents.

\section{Data Abstraction}

Information was extracted through a prespecified data-extraction protocol. From each included study, we collected the following data: 1) immediate and long-term angiographic occlusion, 2) technical success, 3) recanalization rate, 4) retreatment rate, 5) morbidity and mortality related to the procedure, 6) procedurerelated rupture, 7) procedure-related thromboembolism, 8) long-term neurologic outcome, and 9) neurologic outcome at discharge.

The angiographic outcome data were divided into 2 groups: complete or near-complete angiographic occlusion and incomplete occlusion. Results reporting the angiographic findings by using the Raymond grading system (class 1, complete obliteration; class 2, neck remnant; class 3, aneurysm remnant) were translated to our methods as follows: Classes 1 and 2 were considered complete or near-complete angiographic occlusion, and class 3 was included in the incomplete-occlusion group.

The technical success was assessed in only prospective analysis or studies that reported failure of the endovascular treatment attempt. Hemorrhagic or ischemic events were not imputed to rupture or thromboembolism related to the procedure if they were not clearly described as a consequence of the procedure. With

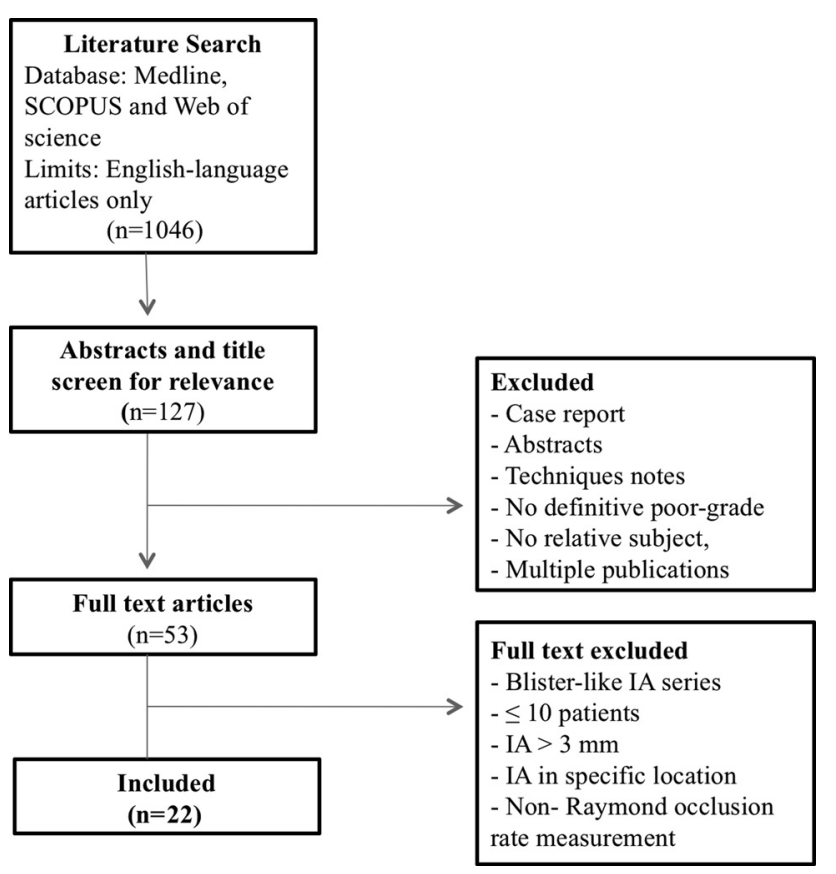

FIG 1. Flow diagram of the search strategy and study selection.

regard to the clinical outcome, only studies using the Glasgow Outcome Scale or the modified Rankin Scale were included. Good neurologic outcome was considered for grades 4 and 5 in the Glasgow Outcome Scale and for grades 0 and 1 in the mRS. Procedure-related morbidity and mortality were defined as morbidity or mortality related to thromboembolic or bleeding complications that occurred during the procedure.

We also compared results from studies included in a previously published meta-analysis from 2010 (time period 1) with more recently published studies (time period 2) to determine whether there were improvements in outcomes with time. ${ }^{7}$ For this comparison, we studied only outcomes of the pooled ruptured/unruptured group.

\section{Statistical Analysis}

All included studies were noncomparative. We estimated from each cohort the cumulative incidence (event rate) and 95\% confidence interval for each outcome. Event rates for each intervention were pooled in a meta-analysis across studies by using the random-effects model. ${ }^{8}$ Anticipating heterogeneity among studies, we chose this model a priori because it incorporates withinstudy variance and between-study variance. Heterogeneity of the treatment effect across studies was evaluated by using the $\mathrm{I}^{2}$ statistic. ${ }^{9}$ We considered an $\mathrm{I}^{2}$ statistic of $>50 \%$ to indicate substantial heterogeneity. We were unable to test for publication bias due to the noncomparative nature of the studies. The metaanalysis was performed by using the statistical software package Comprehensive Meta-Analysis, Version 3.0 (Englewood, New Jersey).

\section{RESULTS}

\section{Characteristics of Included Studies}

The literature search yielded 1046 articles, of which 22 met our inclusion criteria. A summary of the literature search process is 
Table 1: Summary of studies evaluating the endovascular treatment of very small intracranial aneurysms

\begin{tabular}{|c|c|c|c|c|c|c|c|c|}
\hline Study & $\begin{array}{l}\text { No. of } \\
\text { Patients }\end{array}$ & $\begin{array}{l}\text { Patient Age } \\
\text { Range (yr) }\end{array}$ & $\begin{array}{l}\text { Sex } \\
\text { (M/F) }\end{array}$ & $\begin{array}{l}\text { IA Size (mm) } \\
\text { (Mean) }\end{array}$ & $\begin{array}{l}\text { Follow-Up } \\
\text { (mo) (Mean) }\end{array}$ & $\begin{array}{l}\text { No. of } \\
\text { Ruptured } \\
\text { IAs }\end{array}$ & $\begin{array}{l}\text { No. of } \\
\text { Unruptured } \\
\text { IAs }\end{array}$ & $\begin{array}{l}\text { Total No } \\
\text { of IAs }\end{array}$ \\
\hline Suzuki et al, $2006^{22}$ & 21 & $31-86$ & $5: 16$ & 2.6 & 25 & 21 & 0 & 21 \\
\hline Nguyen et al, $2008^{4}$ & 60 & $24-92$ & - & 2.7 & - & 60 & 0 & 60 \\
\hline Chen et al, $2008^{23}$ & 11 & $26-73$ & $8: 3$ & 2.7 & 5.3 & 10 & 1 & 11 \\
\hline van Rooji et al, $2009^{10}$ & 187 & $11-78$ & 51:136 & $\leq 3$ & 6 & 149 & 47 & 196 \\
\hline Yang et al, $2009^{24}$ & 12 & $23-88$ & $4: 8$ & 2.6 & 13.4 & 12 & 0 & 12 \\
\hline Brinjikji et al, $2010^{7}$ & 71 & $37-86$ & $10: 61$ & 2.7 & 10.6 & 24 & 47 & 71 \\
\hline Pierot et al, $2010^{25}$ & 51 & - & $10: 41$ & $\leq 3$ & - & 0 & 51 & 51 \\
\hline Chae et al, $2010^{26}$ & 30 & $28-81$ & 11:19 & $\leq 3$ & 13.3 & 5 & 26 & 31 \\
\hline loannidis et al, $2010^{15}$ & 94 & $27-80$ & $27: 67$ & $\leq 3$ & 23 & 85 & 12 & 97 \\
\hline Fang et al, $2010^{27}$ & 19 & $38-63$ & $5: 14$ & 2.8 & 14.1 & 20 & 0 & 20 \\
\hline Zang et al, $2010^{28}$ & 11 & $25-55$ & $1: 10$ & $\leq 3$ & 7.4 & 10 & 1 & 11 \\
\hline Hwang et al, $2011^{29}$ & 38 & $24-70$ & $12: 26$ & 2.5 & 14.8 & 23 & 20 & 43 \\
\hline Hong et al, $2011^{30}$ & 51 & $17-71$ & $22: 29$ & 2.4 & 14 & 51 & 0 & 51 \\
\hline $\begin{array}{l}\text { Iskandar and } \\
\text { Nepper-Rasmussen, } 2011^{3}\end{array}$ & 107 & - & $34: 73$ & $\leq 3$ & 9 & 87 & 24 & 111 \\
\hline Lu et al, $2012^{11}$ & 46 & $27-83$ & $22: 24$ & 2.5 & 46.7 & 29 & 23 & 52 \\
\hline Mohammadian et al, $2013^{31}$ & 21 & $19-72$ & $22: 18$ & $\leq 3$ & 15 & 21 & 0 & 21 \\
\hline Chung et al, $2013^{32}$ & 72 & - & $24: 48$ & 2.8 & - & 72 & 0 & 72 \\
\hline Starke et al, $2012^{14}$ & 91 & - & $26: 65$ & 2.8 & 9.5 & 91 & 0 & 91 \\
\hline Li et al, $2014^{33}$ & 16 & $33-62$ & $7: 9$ & 1.7 & 7.7 & 16 & 0 & 16 \\
\hline Dalfino et al, $2014^{18}$ & 20 & $27-80$ & 5:15 & 2.7 & 17 & 17 & 3 & 20 \\
\hline Jindal et al, $2015^{34}$ & 12 & $19-70$ & $2: 10$ & 2.25 & 9.25 & 6 & 6 & 12 \\
\hline Yu et al, $2015^{17}$ & 35 & $41-68$ & $23: 12$ & 2.6 & $12-24$ & 35 & 0 & 35 \\
\hline Total & 1076 & & & & & 844 & 261 & 1105 \\
\hline
\end{tabular}

provided in Fig 1. All 22 studies included were single-center case series. Nine studies provided data on only ruptured IAs, 2 provided data on only unruptured IAs, and 11 included both ruptured and unruptured aneurysms. A total of 1105 intracranial aneurysms that received endovascular treatment (844 ruptured and 261 unruptured) were included in this meta-analysis. Stent-assisted coil embolization was performed in 86 cases. Table 1 provides a summary of included studies.

\section{Study Outcomes}

Coil Embolization: Technical Success and Angiographic Outcomes. Technical success for endovascular treatment was achieved in $92 \%$ of the coiled IAs (95\% CI, 88\%-95\%). Immediate postoperative angiography demonstrated a complete occlusion rate of $85 \%$ (95\% CI, 78\%-90\%). At long-term ( $\geq 6$-month) angiographic follow-up, 91\% (95\% CI, 87\%-94\%) of aneurysms had complete or near-complete occlusion. The recanalization rate was $6 \%(95 \% \mathrm{CI}, 4 \%-11 \%)$. The retreatment rate was $7 \%(95 \%$ CI, 5\%-9\%).

When we compared coiled ruptured and unruptured IAs, results from immediate postcoiling angiography demonstrated similar rates of occlusion, with 85\% (95\% CI, 77\%-91\%) for the unruptured coiled group and $88 \%$ (95\% CI, 79\%-93\%) for ruptured aneurysms. For long-term ( $\geq 6$-month) angiographic outcome, $86 \%$ (95\% CI, $80 \%-90 \%)$ of ruptured aneurysms had complete or near-complete occlusion. Overall recanalization and retreatment rates were $6 \%$ and $7 \%$, respectively. Overall long-term ( $\geq 6$-month) occlusion rates were 91\% (95\% CI, $85 \%-94 \%)$.

Coil Embolization: Clinical Outcomes and Complications. Neurologic outcomes were reported at the time of discharge and at long-term ( $\geq 6$-month) follow-up. Eighty-two percent (95\% CI, $64 \%-91 \%)$ of patients were discharged in good neurologic condition. Long-term ( $\geq 6$-month) good neurologic outcome was $79 \%$ (95\% CI, 64\%-89\%). For patients with ruptured IAs, the rate of good neurologic outcome at discharge was $65 \%$ (95\% CI, $30 \%-89 \%)$ and the rate of long-term ( $\geq 6$-month) good neurologic outcome was 74\% (95\% CI, 59\%-85\%). Not enough data were available for individual analysis of unruptured IAs for neurologic outcomes.

With regard to procedure-related complications, intraprocedural rupture was identified in 7\% (95\% CI, 5\%-9\%) of the coiling procedures, while thromboembolic complications occurred in $4 \%(95 \% \mathrm{CI}, 3 \%-6 \%)$ of cases. Coiled ruptured aneurysms had procedure-related rupture in 9\% (95\% CI, 6\%$12 \%$ ) of cases and thromboembolic events in $4 \%$ (95\% CI, $2 \%-9 \%)$. For unruptured IAs, the rate of rupture during coil embolization was $6 \%(95 \% \mathrm{CI}, 3 \%-12 \%)$ and thromboembolic complications occurred in $4 \%$ (95\% CI, 1\%-13\%). The mortality rate related to the coil embolization was 3\% (95\% CI, $2 \%-5 \%)$, while the morbidity rate was $2 \%(95 \% \mathrm{CI}, 2 \%-4 \%)$. For patients with ruptured IAs, the procedure-related mortality and morbidity were $4 \%$ (95\% CI, 2\%-7\%) and 3\% (95\% CI, $2 \%-5 \%)$, respectively. For patients with unruptured aneurysms, procedure-related morbidity was $2 \%$ (95\% CI, $1 \%-$ $12 \%)$ and procedure-related mortality was $2 \%$ (95\% CI, $1 \%-$ 13\%). These data are summarized in Table 2.

Stent-Assisted Coil: Outcomes. Among patients treated with stent-assisted coiling, immediate complete occlusion occurred in $70 \%$ (95\% CI, 52\%-84\%) of cases. Long-term ( $\geq 6$-month) complete occlusion was 93\% (95\% CI, 81\%-98\%). For ruptured IAs, angiographic outcomes showed immediate and 


\begin{tabular}{|c|c|c|c|c|c|c|}
\hline & $\begin{array}{l}\text { Unruptured Aneurysms, } \\
(\%)(95 \% \mathrm{Cl})\end{array}$ & $I^{2}$ & $\begin{array}{l}\text { Ruptured Aneurysms, } \\
(\%)(95 \% \mathrm{Cl})\end{array}$ & $1^{2}$ & $\begin{array}{l}\text { All Aneurysms, } \\
(\%)(95 \% \mathrm{Cl})\end{array}$ & $\mathrm{I}^{2}$ \\
\hline \multicolumn{7}{|l|}{ Complete angiographic occlusion } \\
\hline Initial & 85 (77-91) & 40 & $88(79-93)$ & 71 & $85(78-90)$ & 76 \\
\hline Long-term & $90(44-99)$ & 49 & $86(80-90)$ & 45 & $91(87-94)$ & 45 \\
\hline \multicolumn{7}{|l|}{ Periprocedural outcomes } \\
\hline Rupture & $6(0-13)$ & 0 & $9(6-12)$ & 0 & $7(5-9)$ & 0 \\
\hline Thromboembolism & $4(1-8)$ & NA & $4(2-9)$ & 0 & $4(3-6)$ & 0 \\
\hline Morbidity & $2(1-12)$ & NA & $3(2-5)$ & 0 & $2(2-4)$ & 0 \\
\hline Mortality & $2(1-13)$ & NA & $4(2-7)$ & 0 & $3(2-5)$ & 0 \\
\hline Long-term favorable neurologic outcome & - & - & $74(59-85)$ & NA & $79(64-89)$ & 83 \\
\hline Recanalization & - & - & $9(5-17)$ & 28 & $6(4-11)$ & 54 \\
\hline Retreatment & - & - & $7(3-14)$ & 12 & $7(5-9)$ & 14 \\
\hline
\end{tabular}

Note:-NA indicates not available.

Table 3: Outcomes by time period

\begin{tabular}{|c|c|c|c|}
\hline & $\begin{array}{c}\text { Time Period } 1 \\
\%(95 \% \mathrm{Cl})\end{array}$ & $\begin{array}{c}\text { Time Period } 2 \\
\%(95 \% \mathrm{CI})\end{array}$ & $P$ Value \\
\hline Initial complete/near complete occlusion & $89.0(82.0-96.0)$ & $85.0(79.0-91.0)$ & .004 \\
\hline Initial incomplete occlusion & $9.0(2.0-16.0)$ & $15.0(9.0-21.0)$ & .002 \\
\hline Long-term complete/near complete occlusion & $93.0(90.0-97.0)$ & $94.0(90.0-97.0)$ & .12 \\
\hline Long-term good neurologic outcome & $85.0(74.0-95.0)$ & $77.0(53.0-100.0)$ & .12 \\
\hline Procedure-related morbidity & $2.0(0.0-3.0)$ & $2.0(1.0-3.0)$ & .94 \\
\hline Procedure-related mortality & $2.0(0.0-3.0)$ & $2.0(0.0-3.0)$ & .81 \\
\hline Procedure-related rupture & $7.0(4.0-10.0)$ & $3.0(2.0-4.0)$ & .007 \\
\hline Procedure-related thromboembolism & $1.0(0.0-3.0)$ & $3.0(2.0-5.0)$ & .06 \\
\hline Recanalization & $2.0(0.0-4.0)$ & $5.0(2.0-9.0)$ & .004 \\
\hline Retreatment & $5.0(3.0-8.0)$ & $4.0(2.0-5.0)$ & .93 \\
\hline
\end{tabular}

near-complete occlusion, long-term good neurologic outcome, and recanalization. These data are summarized in Table 2.

\section{DISCUSSION}

Our updated meta-analysis of endovascular coiling of very small intracranial aneurysms demonstrated that coil embolization is effective, with angiographic occlusion rates of $>90 \%$. However, complications rates were not negligible at $6.5 \%$ for ruptured and $5 \%$ for unruptured aneurysms. Intraoperative ruplong-term complete occlusion rates of $68 \%$ (95\% CI, 49\%$82 \%$ ) and $93 \%$ (95\% CI, 79\%-98\%), respectively. Intraprocedural rupture rates were $6 \%(95 \% \mathrm{CI}, 1 \%-34 \%)$, and thromboembolism occurred in 13\% (95\% CI, 4\%-33\%) of cases. The incidence of IA recanalization with stent deployment was $14 \%$ (95\% CI, 4\%-43\%), and the retreatment rate was 3\% (95\% CI, $0 \%-34 \%)$.

Comparison of Outcomes across Time. When we compared outcomes between studies included in the prior meta-analysis and those included in the current meta-analysis, angiographic outcomes were superior in studies included in the prior meta-analysis because initial complete/near-complete angiographic occlusion rates were $89.0 \%$ compared with $85.0 \%$ in recently published series $(P=.004) .{ }^{7}$ Long-term ( $\geq 6$-month) good clinical outcome rates were similar between studies $(93.0 \%$ for time period 1 and $94.0 \%$ for time period 2). Procedure-related rupture rates were significantly lower in more recent studies $(7.0 \%$ versus $3.0 \%, P=$ .007). Retreatment rates were similar between time periods $(5.0 \%$ for time period 1 and $4.0 \%$ for time period 2, $P=.93$ ). These data are summarized in Table 3.

\section{Study Heterogeneity}

No I ${ }^{2}$ statistics were higher than $50 \%$, indicating substantial heterogeneity, for any outcomes in unruptured aneurysms or in stent-assisted coil-treated aneurysms. $\mathrm{I}^{2}$ statistics were higher than $50 \%$, indicating substantial heterogeneity, for the following outcomes in ruptured aneurysms: complete/near-complete initial occlusion and good neurologic outcome at discharge. $\mathrm{I}^{2}$ statistics were higher than 50\%, indicating substantial heterogeneity, for the following outcomes in all aneurysms: initiation complete/ ture rates have decreased with time suggesting that technologic improvements may be enhancing patient outcomes. When we compared earlier experiences with more recent ones, there has been some improvement in complication rates as a result of newer technologic advances ${ }^{5}$ and increased experience, which makes entients with ruptured very small aneurysms. Our results suggest that endovascular treatment of very small unruptured aneurysms should be pursued only in exceptional cases, given the very low risk of rupture of these aneurysms.

Our results showed high rates of complete or near-complete occlusion, both immediately following treatment and at followup. Technical success was achieved in $92 \%$ of patients, and recanalization rates were low. Only $7 \%$ of aneurysms were retreated with coiling or microsurgical clipping. In the prior meta-analysis including 7 studies, we reported slightly higher occlusion rates at short- and long-term, possibly due to factors related to publication and selection bias. ${ }^{7}$ Recently published series are reporting complete occlusion rates as high as $96 \%$ in the immediate postoperative setting and $94 \%$ in the long-term. ${ }^{10}$ Our report might be influenced by different treatment strategies adopted in the included studies. For example, Lu et $\mathrm{al}^{11}$ suggested that complete coil occlusion of the aneurysm sac is not necessary to achieve good long-term outcomes. For challenging aneurysms with a very high rate of intraprocedural rupture, they suggested an initial partial occlusion, allowing progressive stable thrombus formation and complete occlusion in the long-term.

Intraprocedural rupture is a feared complication in the endovascular treatment of tiny aneurysms. ${ }^{4,7,12}$ Nguyen et $\mathrm{al}^{4}$ found a relative risk of intraprocedural rupture of 5.2 (95\% CI, 2.2-12.8) dovascular coil embolization a safe treatment technique in pa- 
when comparing IAs of $\leq 3 \mathrm{~mm}$ versus $>3 \mathrm{~mm}$. However, there have been improvements in the procedural rupture rates with time. In a prior study, we reported an intraprocedural rupture rate of $10.7 \%$ of the ruptured IAs during the coiling procedure compared with $9 \%$ in the current study. ${ }^{7}$ The first large series addressing the endovascular treatment of tiny IAs reported an $11 \%$ rate of procedure-related rupture, 5 times higher compared with larger IAs. ${ }^{4}$ However, recent reports have demonstrated considerably lower risk, with rates of approximately 3\%-4\%. Improvements in technologies with smaller and softer coils, in addition to increased operator experience, have likely contributed to this finding. ${ }^{5}$ New strategies and decisions by operators to avoid procedural rupture, such as partial initial occlusion of the sac as the treatment goal $^{11}$ and a lower threshold to convert to microsurgical clipping, ${ }^{13,14}$ may be contributing to decreasing complication rates as well.

High rates of procedural rupture are expected in the treatment of tiny IAs. The smaller size of the aneurysm sac limits the movement of the microcatheter; thus, any unexpected movement during catheter positioning or coil deployment can result in rupture of the aneurysm sac. ${ }^{10,15}$ Cases of intraprocedural perforation are generally managed through reversal of anticoagulation followed by coiling of the aneurysm. The placement of a balloon at the side of the IA neck to stop hemorrhage has been advocated; however, the use of additional adjunctive devices during treatment of very small intracranial aneurysms has been associated with increased complication rates in some studies. ${ }^{4,10,16}$

Although very helpful in packing coils and, in some cases, diverting flow from the aneurysmal sac, ${ }^{17}$ stent placement has been associated with higher periprocedural complication rates in the endovascular treatment of tiny IAs, as demonstrated in our study. ${ }^{4,18}$ Lower rates of immediate angiographic occlusion were likely due to the less attenuated tamponade required for satisfactory results in stent-coiling procedures. Most interesting, recanalization rates were higher for aneurysms treated with stent-assisted coiling. The higher recanalization rate in the stent-assisted group might be related to antiplatelet therapy required with the use of intraluminal stents and the wider neck size of aneurysms requiring stent-assisted treatment.

In the management of very small unruptured intracranial aneurysms, it is very important to consider the natural history of these aneurysms. Sonobe et $\mathrm{al},{ }^{19}$ reported an annual risk of rupture of $0.34 \%$ and $0.95 \%$ for single and multiple unruptured small aneurysms, respectively. Moreover, on the basis of the Population, Hypertension, Age, Size of Aneurysm, Earlier Subarachnoid Hemorrhage from Another Aneurysm, and Site of (PHASES) Aneurysm score, ${ }^{20}$ patients with aneurysms of $<7 \mathrm{~mm}$ in diameter were subject to $0 \%-7 \%$ risk of rupture within 5 years according to the patient's risk factors. Therefore, the very low probability of rupture in these aneurysms must be considered against the risk of procedural complications and the morbidity/mortality rates related to treatment. Given the low risk of rupture, very small unruptured aneurysms should not be treated except in selected cases. ${ }^{21}$

\section{Limitations}

Our study has limitations. Fifteen of 22 included studies were retrospective; this feature might influence the outcomes pre- sented and increase the publication bias. A wide methodologic variability was found among studies, especially in assessing angiographic and clinical outcomes. Thus, for certain analyses, a limited number of studies were included. Moreover, lack of details about patients also hindered our analysis. The specific locations of IAs were not assessed in this meta-analysis due to lack of available data. Finally, the long-term angiographic and clinical outcomes were evaluated at different times in the studies analyzed. Publication bias is another limitation of this study. Nevertheless, our meta-analysis is currently the largest study assessing the endovascular treatment of very small intracranial aneurysms with $>1000$ included patients.

\section{CONCLUSIONS}

On the basis of our results, we conclude that the coiling of very small intracranial aneurysms can be performed safely and effectively with favorable long-term angiographic and neurologic outcomes. However, complications rates were not negligible at $6.5 \%$ for ruptured and $5 \%$ percent for unruptured aneurysms. These findings highlight the importance of individualized decisionmaking based on aneurysm natural history and treatment risks.

Disclosures: Giuseppe Lanzino-Consultancy: Edge Therapeutics, Covidien/ Medtronic*; Payment for Development of Educational Presentations: Covidien/ ev3*; Travel/Accommodations/Meeting Expenses Unrelated to Activities Listed: Boston Biomedical Associates. Waleed Brinjikji-UNRELATED: grant funding from Brain Aneurysm Foundation, Society of Interventional Radiology, and Society of Neurointerventional Surgery. * Money paid to the institution.

\section{REFERENCES}

1. Molyneux AJ, Birks J, Clarke A, et al. The durability of endovascular coiling versus neurosurgical clipping of ruptured cerebral aneurysms: 18 year follow-up of the UK cohort of the International Subarachnoid Aneurysm Trial (ISAT). Lancet 2015;385:691-97 CrossRef Medline

2. Spetzler RF, McDougall CG, Zabramski JM, et al. The Barrow Ruptured Aneurysm Trial: 6-year results. J Neurosurg 2015;123:609-17 CrossRef Medline

3. Iskandar A, Nepper-Rasmussen J. Endovascular treatment of very small intracranial aneurysms. Interv Neuroradiol 2011;17:299-305 Medline

4. Nguyen TN, Raymond J, Guilbert F, et al. Association of endovascular therapy of very small ruptured aneurysms with higher rates of procedure-related rupture. J Neurosurg 2008;108:1088-92 CrossRef Medline

5. Lim YC, Kim BM, Shin YS, et al. Structural limitations of currently available microcatheters and coils for endovascular coiling of very small aneurysms. Neuroradiology 2008;50:423-27 CrossRef Medline

6. Singh V, Gress DR, Higashida RT, et al. The learning curve for coil embolization of unruptured intracranial aneurysms. AJNR Am J Neuroradiol 2002;23:768-71 Medline

7. Brinjikji W, Lanzino G, Cloft HJ, et al. Endovascular treatment of very small ( $3 \mathrm{~mm}$ or smaller) intracranial aneurysms: report of a consecutive series and a meta-analysis. Stroke 2010;41:116-21 CrossRef Medline

8. DerSimonian R, Laird N. Meta-analysis in clinical trials revisited. Contemp Clin Trials 2015;45(pt A):139-45 CrossRef Medline

9. Higgins JP, Thompson SG, Deeks JJ, et al. Measuring inconsistency in meta-analyses. BMJ 2003;327:557-60 CrossRef Medline

10. van Rooij WJ, Keeren GJ, Peluso JP, et al. Clinical and angiographic results of coiling of 196 very small ( $<$ or $=3 \mathrm{~mm}$ ) intracranial aneurysms. AJNR Am J Neuroradiol 2009;30:835-39 CrossRef Medline

11. Lu J, Liu JC, Wang LJ, et al. Tiny intracranial aneurysms: endovas- 
cular treatment by coil embolisation or sole stent deployment. Eur J Radiol 2012;81:1276-81 CrossRef Medline

12. Sluzewski M, Bosch JA, van Rooij WJ, et al. Rupture of intracranial aneurysms during treatment with Guglielmi detachable coils: incidence, outcome, and risk factors. J Neurosurg 2001;94:238-40 CrossRef Medline

13. Bruneau M, Amin-Hanjani S, Koroknay-Pal P, et al. Surgical clipping of very small unruptured intracranial aneurysms: a multicenter international study. Neurosurgery 2015 Aug 26. [Epub ahead of print] Medline

14. Starke RM, Chalouhi N, Ali MS, et al. Endovascular treatment of very small ruptured intracranial aneurysms: complications, occlusion rates and prediction of outcome. J Neurointerv Surg 2013; 5(suppl 3):iii66-71 CrossRef Medline

15. Ioannidis I, Lalloo S, Corkill R, et al. Endovascular treatment of very small intracranial aneurysms. J Neurosurg 2010;112:551-56 CrossRef Medline

16. Lanzino G, Kallmes DF. Endovascular treatment of very small ruptured intracranial aneurysms. J Neurosurg 2008;108:1087 CrossRef Medline

17. Yu M, Liu F, Jiang S, et al. Stent-assisted coiling for the treatment of ruptured micro-intracranial wide-necked aneurysms. Interv Neuroradiol 2015;21:40-43 CrossRef Medline

18. Dalfino J, Nair AK, Drazin D, et al. Strategies and outcomes for coiling very small aneurysms. World Neurosurg 2014;81:765-72 CrossRef Medline

19. Sonobe M, Yamazaki T, Yonekura M, et al. Small unruptured intracranial aneurysm verification study: SUAVe study, Japan. Stroke 2010;41:1969-77 CrossRef Medline

20. Greving JP, Wermer MJ, Brown RD Jr, et al. Development of the PHASES score for prediction of risk of rupture of intracranial aneurysms: a pooled analysis of six prospective cohort studies. Lancet Neurol 2014;13:59-66 CrossRef Medline

21. Wiebers DO, Whisnant JP, Huston J 3rd, et al; International Study of Unruptured Intracranial Aneurysms Investigators. Unruptured intracranial aneurysms: natural history, clinical outcome, and risks of surgical and endovascular treatment. Lancet 2003;362:103-10 CrossRef Medline

22. Suzuki S, Kurata A, Ohmomo T, et al. Endovascular surgery for very small ruptured intracranial aneurysms: technical note. J Neurosurg 2006;105:777-80 CrossRef Medline
23. Chen Z, Feng H, Tang W, et al. Endovascular treatment of very small intracranial aneurysms. Surg Neurol 2008;70:30-35; discussion 35 CrossRef Medline

24. Yang MS, Wong HF, Yang TH, et al. Alternative option in the treatment of very small ruptured intracranial aneurysms. Surg Neurol 2009;72(suppl 2):S41-46 CrossRef Medline

25. Pierot L, Barbe C, Spelle L, et al. Endovascular treatment of very small unruptured aneurysms: rate of procedural complications, clinical outcome, and anatomical results. Stroke 2010;41:2855-59 CrossRef Medline

26. Chae KS, Jeon P, Kim KH, et al. Endovascular coil embolization of very small intracranial aneurysms. Korean J Radiol 2010;11:536-41 CrossRef Medline

27. Fang $\mathrm{C}$, Li MH, Zhu YQ, et al. The effectiveness and feasibility of endovascular coil embolization for very small cerebral aneurysms: mid- and long-term follow-up. Ann Vasc Surg 2010;24:400-07 CrossRef Medline

28. Zang P, Liang C, Shi Q. Endovascular embolization of very small cerebral aneurysms. Neurol India 2010;58:576-80 CrossRef Medline

29. Hwang JH, Roh HG, Chun YI, et al. Endovascular coil embolization of very small intracranial aneurysms. Neuroradiology 2011;53: 349-57 CrossRef Medline

30. Hong B, Yang PF, Zhao R, et al. Endovascular treatment of ruptured tiny intracranial aneurysms. J Clin Neurosci 2011;18:655-60 CrossRef Medline

31. Mohammadian R, Asgari M, Sattarnezhad N, et al. Endovascular treatment of very small and very large ruptured aneurysms of the anterior cerebral circulation: a single-center experience. Cerebrovasc Dis 2013;35:235-40 CrossRef Medline

32. Chung KH, Herwadkar A, Laitt R, et al. Rate and clinical impact of intra-procedural complications during coil embolisation of ruptured small ( $3 \mathrm{~mm}$ or less) cerebral aneurysms. Clin Neurol Neurosurg 2013;115:1356-61 CrossRef Medline

33. Li CH, Su XH, Zhang B, et al. The stent-assisted coil-jailing technique facilitates efficient embolization of tiny cerebral aneurysms. Korean J Radiol 2014;15:850-57 CrossRef Medline

34. Jindal G, Miller T, Beaty N, et al. Ultra-small diameter coils for treatment of intracranial aneurysms. Interv Neuroradiol 2015;21:50-54 CrossRef Medline 